\title{
ANALISIS FAKTOR-FAKTOR YANG MEMPENGARUHI KESEJAHTERAAN LANSIA DI KECAMATAN MENGWI, KABUPATEN BADUNG
}

\author{
Putu Yunny Lestari Kartini ${ }^{1}$ \\ I Nengah Kartika ${ }^{2}$
}

\author{
Fakultas Ekonomi dan Bisnis Universitas Udayana (Unud), Bali, Indonesia ${ }^{1,2}$ \\ Email:listalestari.11@gmail.com
}

\begin{abstract}
One indicator that reflects the success of development is an increase in the population's life expectancy, which also has an impact on increasing the number of elderly people. The purpose of the study is to analyze the effect of education level, employment status, income, marital status, and simultaneous and partial health access to the welfare of the elderly in Mengwi, Badung. The sample size of 100 seniors from a total of 13,082. Data collection is done through observation, structured interviews and in-depth interviews, analyzed by multiple linear regression. Based on the results, Education Level, Employment Status, Income, Marital Status, and Health Access have a significant and simultaneous influence on the well-being of the elderly. This means that the higher the Education Level, Employment Status, Income, Marital Status, and Health Access of the elderly, the welfare of the elderly in Mengwi, Badung will increase.
\end{abstract}

keywords: elderly; elderly welfare; elderly welfare factors. JEL Classification : J14, D63, I31

\begin{abstract}
ABSTRAK
Salah satu indikator yang mencerminkan keberhasilan pembangunan adalah peningkatan dalam Usia Harapan Hidup (UHH) penduduk, yang juga berdampak pada meningkatnya jumlah lanjut usia. Tujuan penelitian adalah untuk menganalisis pengaruh tingkat pendidikan, status ketenagakerjaan, pendapatan, status perkawinan, dan akses kesehatan secara simultan dan parsial terhadap kesejahteraan lansia di Kecamatan Mengwi, Kabupaten Badung. Ukuran sampel sebanyak 100 orang lansia dari total 13.082. Pengumpulan data dilakukan melalui observasi, wawancara terstruktur dan wawancara mendalam, dianalisis dengan regresi linier berganda. Berdasarkan hasil penelitian, Tingkat Pendidikan, Status Ketenagkerjaan, Pendapatan, Status Perkawinan, dan Akses Kesehatan memiliki pengaruh signifikan secara simultan dan parsial terhadap Kesejahteraan lansia. Hal ini berarti semakin tinggi Tingkat Pendidikan, Status Ketenagkerjaan, Pendapatan, Status Perkawinan, dan Akses Kesehatan yang dimiliki lansia, maka Kesejahteraan lansia di Kecamatan Mengwi, Kabupaten Badung akan mengalami peningkatan.
\end{abstract}

Kata kunci: lansia; kesejahteraan lansia; faktor kesejahteraan lansia. Klasifikasi JEL: J14, D63, I31 
Putu Yunny Lestari Kartini dan I Nengah Kartika. Analisis Faktor-Faktor yang Mempengaruhi.....

\section{PENDAHULUAN}

Pada abad millenium ini terjadi salah satu fenomena kependudukan, yaitu peningkatan jumlah lansia. Aspek ekonomi dan sosial dari populasi yang menua ini sering disebut rasio ketergantungan usia tua yaitu, rasio mereka yang 65 tahun ke atas lebih banyak dibandingkan mereka yang berusia 15-64 tahun (Eshkoor et $a l$, 2015). Proporsi penduduk usia muda atau di bawah 15 tahun mengalami perubahan menjadi mengecil walaupun jumlahnya masih bertambah. Kemajuan pembangunan sebagai bagian dari proses transisi demografi diyakini sebagai faktor signifikan terjadinya perubahan struktur penduduk (McDonald, 2015).

Usia harapan hidup merupakan salah satu indikator keberhasilan program pemerintah seperti, meningkatkan kesejahteraan penduduk pada umumnya, dan meningkatkan derajat kesehatan pada khususnya, namun disatu sisi bertambahnya usia harapan hidup akan menimbulkan berbagai masalah (Rammohan \& Magnani, 2015). Peningkatan jumlah lansia pada dasarnya memberikan dampak positif maupun negatif. Berdampak positif, jika populasi lansia saat dalam keadaan sehat, aktif dan produktif, sedangkan berdampak negatif jika lansia mempunyai masalah penurunan kesehatan yang mengakibatkan peningkatan biaya pelayanan kesehatan, penurunan pendapatan/penghasilan, peningkatan disabilitas, serta tidak terdapatnya dukungan sosial dan lingkungan yang kurang ramah dengan penduduk lansia (Dewi Utami \& Rustariyuni, 2016).

Proyeksi Perserikatan Bangsa-Bangsa (PBB) juga menyebutkan bahwa persentase lansia Indonesia akan mencapai 25 persen pada tahun 2050 atau sekitar 
74 juta lansia. Dalam beberapa tahun ke depan Indonesia akan memasuki penduduk berstruktur lanjut usia (ageing population) yaitu saat persentase penduduk usia 60 tahun keatas mencapai 10 persen (Hukom, 2015). Kondisi ini dikarenakan meningkatnya jumlah penduduk lanjut usia setiap tahunnya, dimana penduduk yang berusia di atas 60 tahun telah mencapai 8,47\% pada tahun 2015 meningkat hampir dua kali lipat jika dibandingkan pada tahun 1971 dengan persentase 4,5 persen (Dharmayanti et al., 2017).

Berdasarkan uraian data diatas, salah satu fenomena kependudukan yang perlu mendapatkan perhatian lebih serius yaitu pertumbuhan penduduk lansia. Jumlah penduduk di Indonesia yang cukup besar, yaitu sebanyak 266.911,9 ribu orang pada tahun 2019 yang mengalami peningkatan jika dibandingkan tahun 2015 yang disajikan pada Tabel 1. Jumlah penduduk yang besar merupakan penyebab jumlah populasi lansia menjadibesar dan menjadi masalah bagi negara, walaupun termasuk rendah jika dibandingkan dengan negara maju (Kurniawan, 2016).

Tabel 1.

Proyeksi Pertumbuhan Penduduk Tahun 2015-2019 (Ribu Orang)

\begin{tabular}{lccccc}
\hline Tahun & $\mathbf{2 0 1 5}$ & $\mathbf{2 0 1 6}$ & $\mathbf{2 0 1 7}$ & $\mathbf{2 0 1 8}$ & $\mathbf{2 0 1 9}$ \\
\hline $\begin{array}{l}\text { Indonesia } \\
\text { Pertumbuhan }\end{array}$ & $255.587,9$ & $258.496,5$ & $261.355,5$ & $264.161,6$ & $266.911,9$ \\
$\begin{array}{l}\text { Penduduk } \\
\text { Sumber: } \text { Data Diolah, 2019 }\end{array}$ & - & 1,13 & 1,09 & 1,06 & 1,03 \\
\hline
\end{tabular}

Kesejahteraan merupaka hal penting untuk lansia karena dengan terpenuhinya kebutuhan yang diperlukan, sehingga dapat memenuhi kualitas hidup lansia. Kualitas hidup yang baik memiliki pengaruh pada cara pandang, 
Putu Yunny Lestari Kartini dan I Nengah Kartika. Analisis Faktor-Faktor yang Mempengaruhi.....

sikap dan perilaku lansia ketika menerima kenyataan hidup dan menikmati hari senjanya tanpa bergantung pada orang lain, sehingga lansia mampu untuk beradaptasi dengan berbagai kemunduran yang terjadi, dan melewati kehidupan dengan bahagia dalam meningkatkan keberfungsian sosial lansia di dalam lingkungannya (Wenas et al., 2015)

Secara luas, banyak penelitian mengenai faktor kesejahteraan, namun hanya sebagian yang selaras dengan hal tersebut, yaitu faktor sosial ekonomi (tingkat pendidikan, jenis pekerjaan, pendapatan, keadaan rumah tangga, tempat tinggal), demografi (umur, jenis kelamin, budaya, statusperkawinan), kualitas anak, kepercayaaan, hubungan sosial atau perilaku, kejadian-kejadian tertentu dalam hidup, kesehatan, dan aktifitas lainnya. Penelitian ini membatasi pada variabel sosial ekonomi pada tingkat pendidikan, status ketenaga kerjaan, dan pendapatan, dan dua variabel lainnya yaitu status perkawinan dan akses kesehatan (Seran, 2017).

Mengacu pada hasil proyeksi penduduk hasil Sensus Penduduk 2010, Indonesia dikatakan struktur penduduk tua setelah tahun 2020, namun beberapa provinsi di Indonesia ternyata sudah mencapai struktur tersebut dimana hasil Survei antar Sensus Penduduk (SUPAS) 2015 menunjukkan ada empat provinsi di Indonesia memiliki persentase lansia lebih dari sepuluh persen, yaitu: DIYogyakarta (13,55 persen), Jawa Tengah (11,72 persen), Jawa Timur (11,52 persen) dan Bali (10,40 persen) dan provinsi yang hampir memasuki ageing population adalah Sulawesi Utara (9,67 persen) (Rahayu \& Tisnawati, 2015). Berdasarkan uraian data tersebut menunjukkan bahwa Bali termasuk ke dalam 
Provinsi dengan struktur penduduk lanjut usia yang memiliki persentase penduduk lansia sebesar 10,40 persen.

Tabel 2.

Angka HarapanHidup Penduduk Provinsi Bali Tahun2014-2018

\begin{tabular}{lccccc}
\hline & \multicolumn{5}{c}{ Indeks Pembangunan Manusia } \\
\cline { 2 - 6 } Kabupaten/Kota & $\mathbf{5 0 1 4}$ & $\mathbf{2 0 1 5}$ & $\mathbf{2 0 1 6}$ & $\mathbf{2 0 1 7}$ & $\mathbf{2 0 1 8}$ \\
\cline { 2 - 6 } Jembrana & 71.39 & 71.43 & 71.57 & 71.7 & 71.91 \\
Tabanan & 72.64 & 72.74 & 72.89 & 73.03 & 73.23 \\
Badung & 74.3 & 74.31 & 74.42 & 74.53 & 74.71 \\
Gianyar & 72.78 & 72.84 & 72.95 & 73.06 & 73.26 \\
Klungkung & 69.91 & 70.11 & 70.28 & 70.45 & 70.7 \\
Bangli & 69.44 & 69.54 & 69.69 & 69.83 & 70.05 \\
Karangasem & 69.18 & 69.48 & 69.66 & 69.85 & 70.05 \\
Buleleng & 70.71 & 70.81 & 70.97 & 71.14 & 71.36 \\
Denpasar & 73.71 & 73.91 & 74.04 & 74.17 & 74.38 \\
\hline Provinsi Bali & $\mathbf{7 1 . 2}$ & $\mathbf{7 1 . 3 5}$ & $\mathbf{7 1 . 4 1}$ & $\mathbf{7 1 . 4 6}$ & $\mathbf{7 1 . 6 8}$ \\
\hline
\end{tabular}

Sumber: Badan Pusat Statistik, 2019

Kabupaten Badung yang berada di Provinsi Bali yang termasuk di dalam provinsi yang memiliki persentase lansia lebih dari sepuluh persen tidak lepas dari peningkatan angka lansia. Kondisi ini terlihat dari peningkatan jumlah harapan untuk bertahan hidup tertinggi diantara 8 Kabupaten dan 1 Kota yang ada di Provinsi Bali. Meningkatnya angka harapan hidup secara tidak langsung mengakibatkan bertambahnya jumlah penduduk lanjut usia dan ada kecenderungan akan meningkat lebih cepat (Ascroft \& Cavanough., 2018) dan angka harapan yang makin hari makin meningkat akan memperlihatkan kemajuan di bidang ekonomi, 
Putu Yunny Lestari Kartini dan I Nengah Kartika. Analisis Faktor-Faktor yang Mempengaruhi.....

memperbaiki lingkunagan hidup serta kemajuan di ilmu pengetahuan trutama untuk ilmu kedokteran (Dewi et al., 2016). Pada Tabel 2 disajikan angka harapan hidup Kabupaten yang cukup tinggidan terdapat peningkatan yangditandai dengan angka harapan hidup semula sebesar 74,3 pada tahun2014 menjadi 74.71 pada tahun 2018.

Meningkatnya jumlah lansia di Kabupaten Badung dapat dilihat pada proyeksi penduduk usia 60 tahun ke atas pada Tabel3. Proyeksi penduduk dibuat mengacu pada hasil Sensus Penduduk 2010 agar dapat menunjang perencanaan pembangunan di masa depan dan sebagai pelengkap data kependudukan yang masih dibutuhkan.

Tabel 3.

ProyeksiPenduduk Usia 60 Tahun Keatas di Kabupaten Badung 2015-2019 (Ribu Jiwa)

\begin{tabular}{lcccccc}
\hline No & Kecamatan & $\mathbf{2 0 1 5}$ & $\mathbf{2 0 1 6}$ & $\mathbf{2 0 1 7}$ & $\mathbf{2 0 1 8}$ & $\mathbf{2 0 1 9}$ \\
\hline 1 & Abiansemal & 9.15 & 9.44 & 9.82 & 10.15 & 10.57 \\
2 & Kuta & 3.4 & 3.7 & 3.9 & 4.14 & 4.42 \\
3 & Kuta Selatan & 6.84 & 7.34 & 7.97 & 8.58 & 9.28 \\
4 & Kuta Utara & 5.55 & 5.92 & 6.35 & 6.75 & 7.24 \\
5 & Mengwi & 11.35 & 11.7 & 12.23 & 12.67 & 13.27 \\
6 & Petang & 2.96 & 3.04 & 3.13 & 3.21 & 3.32 \\
\hline & Total & $\mathbf{3 9 , 2 5}$ & $\mathbf{4 1 , 1 4}$ & $\mathbf{4 3 , 4}$ & $\mathbf{4 5 , 5}$ & $\mathbf{4 8 , 1}$ \\
\hline
\end{tabular}

Sumber: Badan Pusat Statistik, 2019 (data diolah)

Mengacu pada tabel jika proyeksi dari pada populasi lansia yang berada di daerah Badung terjadi peningkatan. Jumlah angka lansia yang makin meningkat 
perlu adanya perhatian dari semua pihak guna mengantisipasi masalah yang akan ditimbulkannya. Penuaan penduduk dapat memberikan implikasi terhadap aspek sosial, aspek ekonomi serta aspek kesehatan. Berdasarkan proyeksi jumlah penduduk usia 60 tahun ke atas menunjukkan jumlah populasi lansia terbanyak berada di Kecamatan Mengwi dengan jumlah sebanyak 13,27 persen sedangkan jumlah penduduk usia 60 tahun ke atas paling sedikit berada pada Kecamatan Petang sebanyak 3,32 persen yang disajikan pada Tabel 3 .

Tujuan dari penelitian ini adalah Untuk menganalisis pengaruh tingkat pendidikan, status ketenagakerjaan, pendapatan, statusperkawinan dan akses kesehatan secara simultan terhadap kesejahteraan lansia di Kecamatan Mengwi dan Untuk menganalisis pengaruh tingkat pendidikan, status ketenagakerjaan, pendapatan, status perkawinan dan akses kesehatan secara parsial terhadap kesejahteraan lansia di Kecamatan Mengwi.

Berdasarkan Peraturan Pemerintah Republik Indonesia Nomor 43 Tahun 2004 tentang Pelaksanaan Upaya Peningkatan Kesejahteraan Sosial Lanjut Usia, yang dimaksud lanjut usia adalah seseorang yang c $_{\text {mencapai usia }} 60$ (enam puluh) tahun ke atas. Lanjut usia dibagi menjadi 2 kelompok, yaitu: 1) Lanjut Usia Potensial adalah lanjut usia yang masih mampu, baik secara fisik maupun psikis, dalam melakukan pekerjaan dan/atau kegiatan yang dapat menghasilkan barang dan/atau jasa dan secara singkat lanjut usia potensial adalah lansia yang masih mampu melakukan kegiatan produktif. 2) Lanjut Usia Tidak Potensial adalah lanjut usia yang tidak berdaya untuk mencari nafkah sehingga hidupnya bergantung pada 
Putu Yunny Lestari Kartini dan I Nengah Kartika. Analisis Faktor-Faktor yang Mempengaruhi.....

orang lain. Lanjut usia tidak potensial tidak mampu melakukan kegiatan produktif akibat keterbatasan kemampuan fisik maupun psikis sehingga mengandalkan bantuan dari orang lain.

Kondisi sejahtera (well-being) menunjuk pada istilah kesejahteraan sosial (social welfare) sebagai kondisi terpenuhinya kebutuhan material dan non-material. Kesejahteraan juga berkaitan dengan terpenuhinya kebutuhan dasar yang tercermin dari rumah yang layak huni, tercukupinya kebutuhan sandang dan pangan, terjangkaunya biaya pendidikan dan kesehatan yang berkualitas. Pada umumnya, kesejahteraan ialah kondisi seseorang yang dapat mengoptimalkan utilitasnya padabatas biaya tertentu dan kondisi terpenuhinya kebutuhan jasmani dan rohani(Hukom, 2014). Kesejahteraan sosial lansia menurut Peraturan Pemerintah Republik IndonesiaNomor 43 Tahun 2004 tentang pelaksanaan upayapeningkatan kesejahteraan sosial lanjut usia adalah suatu tata kehidupan dan penghidupan sosial baik material maupun spiritual yang diliputi oleh rasa keselamatan, kesusilaan, dan ketenteraman lahir batin yangmemungkinkan bagi setiap warga negara untuk mengadakan pemenuhan kebutuhan jasmani, rohani, dansosial yang sebaik-baiknya bagi diri sendiri, keluarga, serta masyarakat dengan menjunjung tinggi hak-hak asasi serta kewajiban manusia sesuaidengan Pancasila.

Teori hirarki kebutuhan Maslow menjadi salah satu tolok ukur yang bisa digunakan dalam memahami kebutuhan manusia yang sangat beragam untuk mencapai kesejahteraan (Ayu Putri dkk., 2017). Orang lanjut usia juga memiliki kebutuhan hidup yang sama agar dapat hidup sejahtera. Kebutuhan tersebut 
diperlukan oleh lanjut usia agar dapat mandiri. Kebutuhan tersebut sejalan dengan pendapat Maslow (1970), ia mengajukan teori tentang hierarchy of needs yang meliputi: Kebutuhan fisiologis (physiological needs), Kebutuhan terhadap rasa aman (the safety needs), Kebutuhan terhadap rasa cinta dan memiliki (the belongingness and love needs), Kebutuhan terhadap penghargaan (the esteem needs), Kebutuhan untuk aktualisasi diri (the needs for self-actualization) (Nurhidayah, 2012).

Tingkat pendidikan adalah suatu proses jangka panjang yang menggunakan prosedur sistematis dan terorganisir, yang mana tenaga kerja manajerial mempelajari pengetahuan konseptual dan teoritis untuk tujuan-tujuan umum (Mangkunegara dalam Kartika Candra, 2016). Tingkat pendidikan terdiri dari: 1) Pendidikan dasar, ialah jenjang pendidikan awal selama 9 tahun pertama masa sekolah anak-anak untuk melandasi jenjang pendidikan menengah, 2) Pendidikan menengah, ialah jenjang pendidikan lanjutan pendidikan dasar, 3) Pendidikan tinggi, ialahjenjang pendidikan setelah pendidikan menengah yang mencakup program sarjana, magister, dan spesialis yang diselenggarakan oleh perguruan tinggi.

Tenaga kerja adalah pendudukyang termasuk dalam usia kerja. Menurut UU No. 13 tahun 2003 Bab I pasal 1 ayat 2 disebutkan bahwa tenaga kerja adalah seseorang yang mampu melakukan pekerjaan untuk menghasilkan barang dan atau jasa baik agar dapat mencukupi kebutuhan sendiri ataupun masyarakat. Secara garis 
Putu Yunny Lestari Kartini dan I Nengah Kartika. Analisis Faktor-Faktor yang Mempengaruhi.....

besar penduduk dibedakan menjadi 2 kelompok, yaitu tenaga kerja dan bukan tenaga kerja.

Menurut BPS, status perkawinan diklasifikasikan menjadi 4 (empat), yaitu: (i) Belum kawin, yaitu status dari penduduk yang lajang atau belum menikah; (ii) Kawin, yaitu status dari penduduk yang berstatus kawin pada saat pencacahan, baik tinggal bersama maupun terpisah, penduduk yang kawin sah secara hokum (adat, agama, hukum, dan sebagainya), dan penduduk yang hidup bersama dan oleh masyarakat sekitarnya dianggap sebagai suami/istri; (iii) Cerai hidup yaitu status dari individu yang telah berpisah sebagai suami-istri karena bercerai dan belum kawin lagi, termasuk seseorang yang mengaku cerai namun belum resmi secara hukum; dan (iv) Ceraii mati, yaitu status individu yang ditinggal mati oleh suami atau istrinya dan belum kawin lagi.

Menurut Jones pengertian akses pelayanan kesehatan adalah kemampuan seseorang untuk mencari pelayanan kesehatan yang dibutuhkan. Akses pelayanan kesehatan medis dapat diukur dengan ketersediaan sumber daya dan jumlah orang yang mempunyai asurans untuk membaya penggunaan sumber daya. Gulliford et al., (2002) menguraikan gagasan untuk mengukur aksesibilitas pelayanan kesehatan berdasarkan pemanfaatannya, yang tergantung pada keterjangkauan, aksesibilitas fisik, dan pelayanan yang diterima, bukan hanya pada masalah kecukupan supply.

Penelitian Sudibia \& Kartika (2015) menyatakan bahwa variabel tingkatpendidikan memberi pengaruh positif terhadap akses kesehatan penduduk 
lanjut usia. Tingkat pendidikan yang semakin tinggi didapatkan maka semakin luas wawasan dan pengetahuan yang dimiliki penduduk lansia yang membuat lansia lebih peduli pada kesehatan dancermat untuk menentukkan dan menggunakan akses pelayanan kesehatan.

Penelitian Sudibia \& Kartika (2015) menyatakan status ketenagakerjaan memberi pengaruh positif terhadap akses kesehatan penduduklanjut usia. Status ketenagakerjaan berhubungan terhadap pendapatan yang dimiliki agar lansia dapat mencukupi kebutuhan kesehatan. Bagi lansia yang masih bekerja dan masih memiliki pendapatan lebih mudah untuk mendapatkan akses pelayanan kesehatan dibandingkan dengan lansia yang tidak bekerja dan tidak memiliki pendapatan yang tetap.

Kim et al., (2017) menyatakan faktor kondisi ekonomi memiliki hubungan yang positif terhadap kesejahteraan lansia. Tercukupinya kebutuhan hidup membuat penduduk lansia akan semakin sejahtera (Sriastiti, 2018). Menurut Thomas et al. (2017), "pernikahan terutama dalam masyarakat tradisional, adalah sumber dukungan sosial yang kuat bagi pasangan dengan tingkat kesejahteraan yang tinggi. Lansia yang memiliki pasangan merupakan lansia dengan tingkat kesejahteraan yang lebih baik karena mendapatkan dukungan dari hubungan yang terjalin dengan pasangan dan terhindar dari perasaan kesepian.”

Penelitian Huang et al., (2019) juga menyatakan "akses kesehatan berpengaruh positif dan signifikan terhadap kesejahteraan penduduk lansia. Dengan hidup sehat dan jarang mengalami sakit, penduduk lansia dapat menikmati hari- 
Putu Yunny Lestari Kartini dan I Nengah Kartika. Analisis Faktor-Faktor yang Mempengaruhi.....

harinya dengan tenang tanpa harus menderita. Penduduk lanjut usia yang memiliki akses kesehatan yang baik akan dapat menjalani hidupnya dengan sehat dan sejahtera."

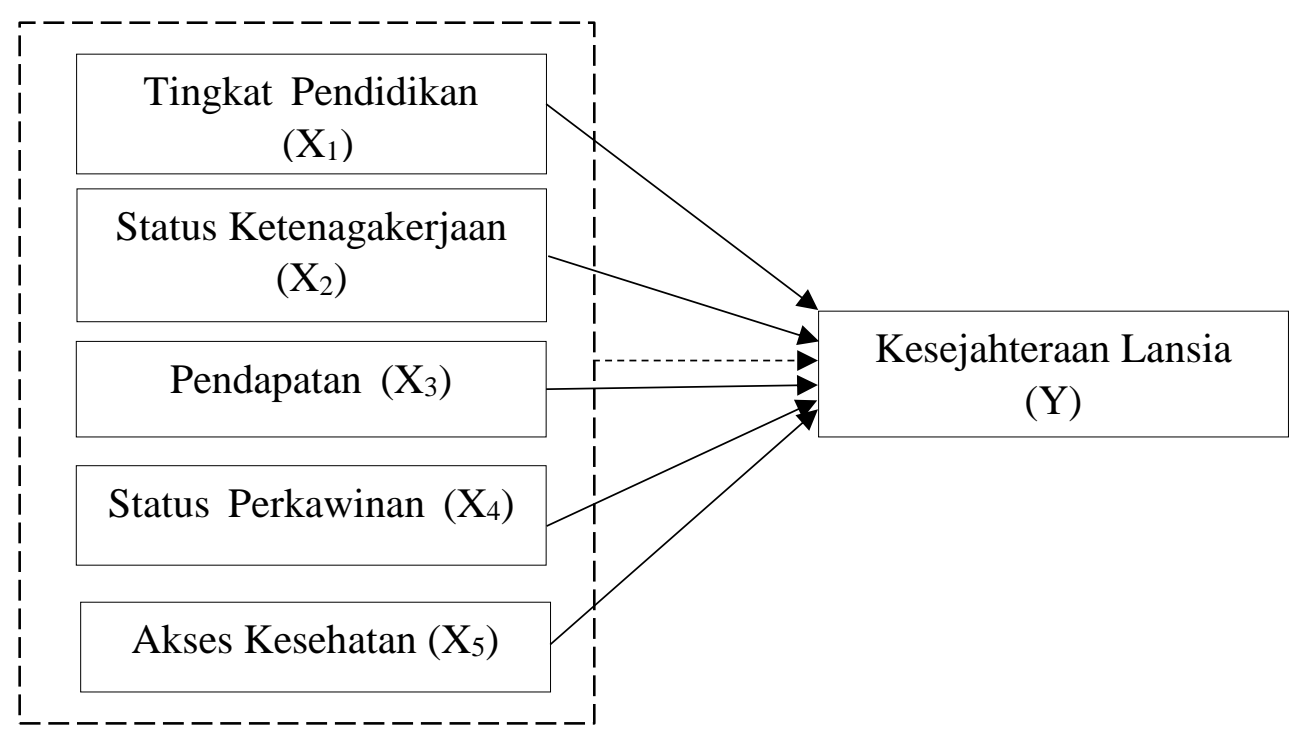

Gambar 1.

Kerangka Konseptual Faktor-faktor yang Mempengaruhi Kesejahteraan Lansia

Mengacu pada landasan teori serta hasil peneltian sebelumnya yang relevan, hipotesis dari peneltian ini adalah:

H1: Tingkat penddikan, status ketenagakerjaan, pendapatan, status perkawinandan akses kesehatan secara simultan memberi pengaruh positif terhadap kesejahteraan lansiadi Kecamatan Mengwi.

H2: Diduga tingkatpendidikan secara parsial memberi pengaruh positif terhadap kesejahteraan lansia di Kecamatan Mengwi.

H3: Diduga lansia yang bekerja memiliki tingkat kesejahteraan lebih tinggi di bandingkan dengan lansia yang sudah tidak bekerja di Kecamatan Mengwi. 
H4: Diduga pendapatan secara parsial memberi pengaruh positif terhadap kesejahteraan lansia di Kecamatan Mengwi.

H5: Diduga Lansia yang berstatus kawinmemiliki tingkat kesejahteraan lebih tinggi di bandingkan dengan lansia yangberstatus belum menikah/janda/duda di Kecamatan Mengwi.

H6: Diduga lansia yang memiliki akses kesehatan memiliki tingkat kesejahteraan lebih tinggi di bandingkan dengan lansia yang tidak memiliki akses kesehatan di Kecamatan Mengwi.

\section{METODE PENELITIAN}

Dalam penelitian ini, digunakan desain penelitian kuantitatif dengan pendekatan asosiatif. Penelitian ini dilaksanakan di Kecamatan Mengwi. Dalam penelitian ini variabel terikatnya adalah kesejahteraan lansia (Y). Dalam penelitian ini, menggunakan empat variabel bebas yaitu: tingkat pendidikan $\left(\mathrm{X}_{1}\right)$, status ketenagakerjaan $\left(\mathrm{X}_{2}\right)$, pendapatan $\left(\mathrm{X}_{3}\right)$, status perkawinan $\left(\mathrm{X}_{4}\right)$, dan akses kesehatan $\left(\mathrm{X}_{5}\right)$. Dalam penelitian ini data kuantitatif mencakup tingkat pendidikan, status ketenagakerjaan, pendapatan, status perkawinan, dan akses kesehatan.

Dalam penelitian ini sumber data diperoleh dari responden yaitu lanjut usia (lansia) di Kecamatan Mengwi melalui wawancara terstruktur pada responden. Data sekunder diperoleh dari Badan Pusat Statistik, kantor camat Mengwi, Dinas Sosial Kabupaten Badung dan masing-masing lingkungan. Metode pengumpulan data yang digunakan adalah observasi, wawancara terstruktur, dan wawancara mendalam. Populasi dalam penelitian ini adalah seluruh penduduk yang berumur 
Putu Yunny Lestari Kartini dan I Nengah Kartika. Analisis Faktor-Faktor yang Mempengaruhi.....

60 tahun ke atas di Kecamatan Mengwi sebanyak 13.082 orang lansia di Kecamatan Mengwi, sehingga sampel yang digunakan diambil dengan menggunakan rumus Slovin, yaitu:

$$
n=\frac{N}{1+N e^{2}}=\frac{13.082}{1+13.082 \times 0,1^{2}}=\frac{13.082}{1+130,82}=99,24=100 \text { (dibulatkan) }
$$

Dengan batas kesalahan 10 persen maka didapat sampel dalam penelitian ini sebanyak 100 orang lansia di Kecamatan Mengwi yang selanjutnya cara untuk menentukan sampel yaitu memakai teknik nonprobability sampling dengan metode accidental sampling dan metode snowball sampling yang dilakukan dengan penentuan sampel berdasarkan kebetulan/accidental bertemu dengan peneliti dapat digunakan sebagai sampel, bila dipandang orang yang kebetulan ditemui itu cocok sebagai sumber data. Ukuran jumlah sampel dapat ditunjukan pada Tabel 4.

Tabel 4.

Ukuran Jumlah Sampel

\begin{tabular}{clcc}
\hline No & \multicolumn{1}{c}{ Desa } & Jumlah Lansia & Jumlah Sampel \\
\hline 1 & Abianbase & 569 & 4 \\
2 & Baha & 371 & 3 \\
3 & Buduk & 709 & 5 \\
4 & Cemagi & 597 & 4 \\
5 & Gulingan & 893 & 7 \\
6 & Kapal & 1.279 & 10 \\
7 & Kekeran & 465 & 4 \\
8 & Kuwum & 353 & 3 \\
9 & Lukluk & 763 & 6 \\
10 & Mengwi & 906 & 7 \\
11 & Mengwitani & 906 & 7 \\
12 & Munggu & 851 & 6 \\
13 & Penarungan & 747 & 6 \\
14 & Pererenan & 382 & 3 \\
15 & Sading & 701 & 5 \\
16 & Sembung & 502 & 4 \\
17 & Sempidi & 508 & 4 \\
18 & Sobangan & 528 & 4 \\
19 & Tumbak Bayuh & 562 & 4 \\
20 & Werdi Bhuana & 490 & 4 \\
\hline Jumlah & & $\mathbf{1 3 . 0 8 2}$ & $\mathbf{1 0 0}$ \\
\hline Sumber: Data Diolah, 2019 & &
\end{tabular}


Dalam penelitian ini teknik analisis data yang dipakai adalah regresi linear berganda, teknik ini dipakai untuk mengetahui pengaruh antara variabel bebas (independent) yaitu tingkat pendidikan, status ketenagakerjaan, pendapatan, statusperkawinan, dan akses kesehatan terhadap variabel terikat (dependent) yaitu kesejahteraan lansia di Kecamatan Mengwi, Kabupaten Badung. Teknik analasis yang dilakukan yaitu dengan metode analisis regresi linier berganda, uji koefisien determinasi, uji asumsi klasik, dan uji secara simultan dan parsial.

$Y=\alpha+\beta_{1} X_{1}+\beta_{2} X_{2}+\beta_{3} X_{3}+\beta_{4} X_{4}+\beta_{5} X_{5}+e$

\section{HASIL DAN PEMBAHASAN}

Pengujian validitas pada penelitian ini ialah derajat ketepatan antara datayang sebenarnya terjadi pada objekpenelitian terhadap data yang dilaporkan oleh peneliti. Data dikatakan valid jika hasil data "yang tidak berbeda" antara data yang dilaporkan oleh peneliti dengandata yang sebenarnya terjadi pada objek penelitian. Pada hasil output SPSS item total statistic, apabila nilai Pearson Correlation > 0,300, maka dikatakan valid.

Setiap item pertanyaan dari variabel yang digunakan yaitu Kesejahteraan Lansia (Y), pada kuisioner memiliki nilai Pearson Product Moment (r) yang lebih besar dari pada 0,300 sehingga pertanyaan dalam kuisioner yang digunakan dinyatakan valid. Hasil perhitungan uji validitas variabel kesejahteraan lansia dengan 10 butir pertanyaan dapat ditunjukan pada Tabel 5 . 
Tabel 5.

Hasil Uji Validitas Variabel Kesejahteraan Lansia (Y)

\begin{tabular}{cccc}
\hline $\begin{array}{c}\text { Variabel tPenelitian } \\
\text { t }\end{array}$ & Pertanyaan t & $\begin{array}{c}\text { Pearson } \\
\text { tProduct } \\
\text { tMoment } \boldsymbol{t}\end{array}$ & $\begin{array}{c}\text { Syarat } \\
\text { tValiditas t }\end{array}$ \\
\hline & Y1 & 0.911 & 0.300 \\
Y2 & 0.851 & 0.300 \\
& Y3 & 0.687 & 0.300 \\
Kesejahteraan Lansia (Y) & Y4 & 0.863 & 0.300 \\
& Y5 & 0.445 & 0.300 \\
& Y6 & 0.791 & 0.300 \\
& Y7 & 0.731 & 0.300 \\
& Y8 & 0.805 & 0.300 \\
& Y9 & 0.765 & 0.300 \\
& Y10 & 0.701 & 0.300 \\
\hline
\end{tabular}

Sumber: Data Primer (diolah), 2020

Uji reliabilitas digunakan agar mengetahui sejauh mana hasil perhitungan tetap konsisten jika dilakukan dua kali atau lebih dengan gejala yang sama dan memakai alatukur yang sama. Jika nilai Cronbach's Alpha $>0,700$ maka dapat dikatakan jika hasil pengukuran variabel tersebut reliabel.

Nilai Cronbach's Alpha masing-masing variabel pada kuisioner Kesejahteraan Lansia (Y) sebesar 0,905 Nilai Cronbach's Alpha yang dihasilkan setiap variabel lebih besar dari 0,700 sehingga dapat disimpulkan bahwa kuisioner yang digunakan sudah reliabel. Pengujian reliabilitas menggunakan program SPSS ditunjukan pada Tabel 6 .

Tabel 6.

Hasil Uji Reliabilitas Variabel Kesejahteraan Lansia (Y)

\begin{tabular}{cccc}
\hline Variabel Penelitian & $\begin{array}{c}\text { Cronbach's } \\
\text { Apha }\end{array}$ & $\begin{array}{c}\text { Syarat Cronbach's } \\
\text { Apha }\end{array}$ & Keterangan \\
\hline Kesejahteraan Lansia (Y) & 0.905 & 0.700 & Reliabel \\
\hline Sumber:
\end{tabular}

Sumber: Data Primer (diolah), 2020 
Uji normalitas digunakan untuk menguji model regresi variabel bebas dan variabel terikat berdistribusi normal atau tidak dengan uji statistik. Pengujian normalitas nilairesidual terhadap penelitian ini dilakukan menggunakan metode One-Sample Kolmogrov-SmirnovTest. Jika nilai Asymp. Sig. (2-tailed) > 0,05 (alpha) maka semuadata dalam penelitian dapat dikatakan berdistribusi normal.

Hasil uji Kolmogorov-Smirnov menunjukkan bahwa nilai Asymp. Sig. (2tailed) yang dihasilkan adalah sebesar 0,146. Nilai yang dihasilkan ini >0,05 sehingga dapat dikatakan data mengikuti sebaran normal, sehingga asumsi normalitas dapat terpenuhi.

Tabel 7.

Hasil Uji Normalitas One-Sample Kolomogrov-Smirnov Test

\begin{tabular}{llr}
\hline & & $\begin{array}{c}\text { Unstandardized } \\
\text { Residual }\end{array}$ \\
\hline $\mathrm{N}$ & Mean & 100 \\
Normal Parameters & Std. Deviation & .0000000 \\
Most Extreme Differences & Absolute & .10598841 \\
& Positive & .077 \\
Test Statistic & Negative & .056 \\
Asymp. Sig. (2-tailed) & & -.077 \\
& & .077 \\
& & $\underline{\mathbf{. 1 4 6}}$
\end{tabular}

Sumber: Data Primer (diolah), 2020

Uji multikolinearitas digunakan untuk mengetahui apakah terdapat variabel bebas yang mempunyai kemiripan dengan variabel bebas lainnya dalam satu model yang menjadi penyebab terjadinya korelasi yang kuat antara satu variabel bebas dengan variabel lain. Multikolinearitas dapat dilihat dari nilai tolerance atau nilai variance inflation factor(VIF). Jika nilai tolerance $>0,10$ atau VIF $<10$ maka 
Putu Yunny Lestari Kartini dan I Nengah Kartika. Analisis Faktor-Faktor yang Mempengaruhi.....

disimpulkan bahwa tidak ada multikolinearitas. Mengacu pada Tabel 4, bahwa tidak terdapat variabel bebas yang memiliki nilai tolerance $<0,10$ yang berarti tidak terdapat korelasi antara variabel bebas. Hasil perhitungan nilai VIF juga menunjukkkan hal yang sama, sehingga tidak ada satu variabel bebas yang memiliki nilai VIF >10. Hal ini berarti bahwa tidak ada gejala multikolinearitas dari model regresi yang dibuat.

Tabel 8.

Hasil Uji Multikolinieritas

\begin{tabular}{|c|c|c|c|c|}
\hline No & Variabel & Tolerance & VIF & Keterangan \\
\hline 1 & Tingkat Pendidikan & 0,789 & 1,267 & Tidak terdapat multikolinieritas \\
\hline 2 & Status Ketenagakerjaan & 0,425 & 2,355 & Tidak terdapat multikolinieritas \\
\hline 3 & Pendapatan & 0,669 & 1,494 & Tidak terdapat multikolinieritas \\
\hline 4 & Status Perkawinan & 0,458 & 2,186 & Tidak terdapat multikolinieritas \\
\hline 5 & Akses Kesehatan & 0,863 & 1,159 & Tidak terdapat multikolinieritas \\
\hline
\end{tabular}

Sumber: Data Primer (diolah), 2020

Uji heteroskedastisidas bertujuan untuk menguji apakah dalam model regresi terdapat ketidaksamaan varians dari residual dari satu pengamatan ke pengamatan lain. Model regresi dikatakan tidak mengandung heteroskedastisitas jika nilai signifikansi variabel independennya terhadap nilai absolute residual statistik di atas $>\alpha=0,05$. Mengacu pada Tabel 9 dapat dilihat bahwa semua variabel bebasnya mempnyai nilai sig $>0,05$ ini berarti pada model regresi tidak terjadi gejala heteroskedasitisitas. 
Tabel 9.

Hasil Uji Heteroskedastisitas

\begin{tabular}{clcl}
\hline No & Variabel & Sig. & Kesimpulan \\
\hline 1 & Tingkat Pendidikan & 0,252 & Tidak terdapat heteroskedastisitas \\
2 & Status Ketenagakerjaan & 0,317 & Tidak terdapat heteroskedastisitas \\
3 & Pendapatan & 0,672 & Tidak terdapat heteroskedastisitas \\
4 & Status Perkawinan & 0,900 & Tidak terdapat heteroskedastisitas \\
5 & Akses Kesehatan & 0,707 & Tidak terdapat heteroskedastisitas
\end{tabular}

Sumber: Data Primer (diolah), 2020

Dalam penelitian ini model analisi yang digunakan ialah regresi linear berganda dengan memakai alat bantu SPSS. Model analisis regresi linier berganda digunakan agar mengetahui pengaruh tingkat pendidikan, status ketenagakerjaan, pendapatan, status perkawinan, dan akses kesehatan terhadap kesejahteraan lansia di Kecamatan Mengwi yang terdiri dari uji F (secara simultan) dan uji t (secara parsial).

Tabel 10.

Hasil Uji Analisis Regresi Linear Berganda

\begin{tabular}{|c|c|c|c|c|c|c|}
\hline & \multirow[b]{2}{*}{ Model } & \multirow{2}{*}{\multicolumn{3}{|c|}{$\begin{array}{cc} & \text { Standardize } \\
\text { dized } & \text { d } \\
\text { nts } & \text { Coefficients } \\
\text { Std. } & \\
\text { Error } & \text { Beta } \\
\end{array}$}} & \multirow[b]{2}{*}{$\mathbf{t}$} & \multirow[b]{2}{*}{ Sig. } \\
\hline & & & & & & \\
\hline \multirow{6}{*}{1} & (Constant) & 2,807 &, 252 & & 11,148 & ,000 \\
\hline & Tingkat Pendidikan &, 044 & ,019 &, 178 & 2,369 &, 020 \\
\hline & $\begin{array}{c}\text { Status } \\
\text { Ketenagakerjaan }\end{array}$ & ,090 & ,034 & ,268 & 2,609 &, 011 \\
\hline & Pendapatan & 053 & ,019 & ,231 & 2,827 &, 006 \\
\hline & Status Perkawinan & ,087 & ,033 & ,262 & 2,648 & ,010 \\
\hline & Akses Kesehatan & 059 & 027 & ,156 & 2,170 &, 033 \\
\hline
\end{tabular}


Putu Yunny Lestari Kartini dan I Nengah Kartika. Analisis Faktor-Faktor yang Mempengaruhi.....

Hasil olahan data memakai program SPSS mendapatkan persamaan regresi linier berganda yaitu:

$Y=2,807+0,044 X_{1}+0,090 X_{2}+0,053 X_{3}+0,087 X_{4}+0,059 X_{5}$

Dari hasil pengolahan data SPSS, didapatkan nilai $R$-Square sebesar 0,577 atau sebesar 55,7 persen. Hal tersebut berarti 55,7 persen variasi (naik turunnya) kesejahteraan lansia di Kecamatan Mengwi dipengaruhi oleh variasi (naik turunnya) tingkat pendidikan, status ketenagakerjaan, pendapatan, status perkawinan, dan akses kesehatan, sedangkan 43,0 persen dipengaruhi dengan variabel lain yang tidak dimasukkan dalam model penelitian.

Mengacu pada hasil analisis regresi secara simultan F hitung $(25,938)$ melebihi $\mathrm{F}$ tabel $(2,47)$ dengan sig $0,000<0,05$ sehingga penolakan $\mathrm{H}_{0}$ dan penerimaan $\mathrm{H}_{1}$. Hasil peneltian ini memberi gambaran jika tingkat pendidikan, status ketenagakerjaan, pendapatan, status perkawinan, dan akses kesehatan secara simultan memberi pengaruh terhadap kesejahteraan lansia di Kecamatan Mengwi.

Hasil penelitian ini selaras dengan penelitian Yamada et al., (2015) yang menunjukkan bahwa tingkat pendidikan, status ketenagakerjaan, pendapatan, status perkawinan dan akses kesehatan berpengaruh terhadap kesejahteraan lansia. Hasil penelitian ini menggambarkan bahwa lansia yang memiliki riwayat pendidikan yang lebih tinggi, memiliki lebih banyak pengetahuan, sehingga mempunyai bekal untuk mendapatkan kesempatan memiliki pekerjaan yang layak. Memiliki pekerjaan yang baik membuat lansia dapat memiliki penghasilan yang cukup, maka 
pada masa pensiun lansi mampu mendapatkan uang pensiun yang mampu digunakan dan dimanfaatkan untuk mencukupi kebutuhan hidup.

Keadaan ini dapat didukung dengan kualitas pernikahan yang baik, yang akan membawa lansia mencapai kesejahteraan yang lebih tinggi. Selain itu, pendidikan yang tinggi akan membuat lansia memiliki pengetahuan yang lebih baik terkait tentang masalah kesehatan, yang mengarah ke kondisi kesehatan yang lebih baik dan kepemilikan akses kesehatan yang akan menghasilkan tingkat kesejahteraan yang lebih tinggi.

Mengacu pada uraian diatas, sehingga hal ini sesuai dengan pengujian hipotesis satu yaitu variabel tingkat pendidikan, status ketenagakerjaan, pendapatan, status perkawinan, dan akses kesehatan secara simultan memberi pengaruh positif terhadap kesejahteraan lansia di Kecamatan Mengwi.

Mengacu pada hasil analisis regresi linear berganda secara parsial tingkat pendidikan $\left(\mathrm{X}_{1}\right)$ mendapatkan $\mathrm{t}$ hitung $(2,369)$ melebihi t tabel $(1,985)$ dengan sig $0,02<0,05$ sehingga penolakan $\mathrm{H}_{0}$ dan penerimaan $\mathrm{H}_{1}$. Hasil peneltian ini memberi gambaran jika tingkat pendidikansecara parsial memberi pengaruh positif dan signfikan terhadapkesejahteraan lansiadi Kecamatan Mengwi. Nilai koefisien regresi dari tingkat pendidikan $\left(\mathrm{X}_{1}\right)$ adalah sebesar 0,044 yang berarti apabila terjadi peningkatan tahun sukses pendidikan seorang lansia sebesar 1 tahun dapatmeningkatkan kesejahteraan lansia sebesar 0,044 persen denganasumsi variabel lain bernilai konstan. 
Putu Yunny Lestari Kartini dan I Nengah Kartika. Analisis Faktor-Faktor yang Mempengaruhi.....

Hasil penelitian ini menggambarkan bahwa semakin tinggi pendidikan yang dilewati lansia pada masa lalunya berpengaruh terhadap kesejahteraan lansia yang lebih baik di masa kini. Penelitian ini didukung oleh hasil penelitian dari Aini et al., (2018) yang menunjukka bahwa tingkat pendidikan berpengaruh positif dan signifikan terhadap kesejahteraan. Melalui pendidikan, lansia dapat memiliki wawasan yang luas dan ilmu pengetahuan agar dapat mengembangkan keahlian dalam diri untuk mendapatkan kehidupan yang sejahtera. Pendidikan yang tinggi juga berhubungan dengan pengetahuan lansia yang lebih baik mengenai masalah kesehatan, yang mengarah ke kondisi kesehatan yang lebih baik dan akibatnya, menghasilkan tingkat kesejahteraan yang lebih tinggi (Calys-Tagoe et al., 2015)

Selain itu hasi penelitian ini diperkuatdengan hasil wawancara yang dilakukan terhadap seorang lansia berinisial NKA yang berdomisili di Desa Tumbak Bayuh. Berdasarkan hasil wawancara tersebut bahwa tingkat pendidikan merupakan faktor penting dalam mempengaruhi kesejahteraan lansia. Semakin tinggi tingkat pendidikan lansia, maka lansia tersebut semakin mampu mengembangkan potensi dirinya untuk mencapai kesejahteraan walaupun dalam usia senja.

Mengacu pada uraian diatas, sehingga hal ini sesuai dengan pengujian hipotesis dua yaitu variabel tingkat pendidikansecara parsial memberi pengaruh positif terhadap kesejahteraan lansia di Kecamatan Mengwi.

Mengacu pada hasil analisis regresi linear berganda secara parsial status ketenagakerjaan $\left(\mathrm{X}_{2}\right)$ mendapatkan $\mathrm{t}$ hitung $(2,609)$ melebihi $\mathrm{t}$ tabel $(1,985)$ dengan 
sig $0,011<0,05$ sehingga penolakan $\mathrm{H}_{0}$ dan penerimaan $\mathrm{H}_{1}$. Hasil peneltian ini memberi gambaran jika lansia yang bekerja memiliki tingkat kesejahteraan lebih tinggidi bandingkan dengan lansia yang sudah tidak bekerja di Kecamatan Mengwi.

Nilai koefisien regresi dari status ketenagakerjaan $\left(\mathrm{X}_{2}\right)$ adalah sebesar 0,090 yang artinya jika lansia yang bekerja $(D=1)$ mempunyai kesejahteraan lebih tinggi sebesar 0,090 persen jika dibandingkan lansia yang tidakbekerja $(D=0)$. Dalam penelitian ini menyatakan bahwa terdapat perbedaan antara lansia yang bekerja dan tidak bekerja.

Hasil penelitian ini menggambarkan jika lansia yang masih bekerja pada masa tuanya lebih sejahtera dibandingkan dengan lansia yang tidak bekerja. Penelitian ini didukung oleh hasil penelitian dari Adebowale et ali., (2015) yang menunjukka status pekerjaan memberi pengaruh positif dan signifikan terhadap kesejahteraan. Banyak alasan yang diungkapakan lansia untuk masih tetap bekerja dalam usia senja, namun alasan terbesar lansia masih bekerja adalah untuk menambah penghasilan dan membantu keuangan keluarga, dan pekerjaan yang paling banyak ditekuni adalah pekerjaan kasar seperti buruh tani, buruh bangunan, dan sebagian lagi pedagang.

Jumlah lansia yang masih bekerja terhitung banyak, hali ini disebabkan oleh kebutuhan ekonomi yang relatif masih besar, serta secara fisik dan mental lansia tersebut masih mampu melakukan aktivitas sehari-hari. Lansia yang tidak bekerja akan lebih memiliki sedikit kegiatan dan banyak waktu luang. Sedikitnya kegiatan 
Putu Yunny Lestari Kartini dan I Nengah Kartika. Analisis Faktor-Faktor yang Mempengaruhi.....

ini akan menimbulkan rasa bosan pada lansia yang dapat mengakibatkan terjadinya depresi.

Berdasarkan hasil wawancara dengan narasumber bahwa status ketenagakerjaan merupakan faktor penting dalam mempengaruhi kesejahteraan lansia. Bekerja menyebabkan penduduk lansia mampu lebih mandiri untuk mencukupi kebutuhan sehari-hari dan memiliki aktivitas untuk menhilangkan rasa jenuh jika dibandingkan terhadap lansia yang tidak bekerja. Bekerja untuk lansia dapat meningkatkan hubungan lansia terhadap orang lain yang mampu memunculkan rasa senang untuk menghindari diri dari rasakesepian.

Mengacu pada uraian diatas, maka hal ini sesuai dengan pengujian hipotesis tiga yaitu lansia yang bekerja memiliki tingkat kesejahteraan lebih tinggi di bandingkan dengan lansia yang sudah tidak bekerja di Kecamatan Mengwi.

Mengacu pada hasil analisis regresi linear berganda secara parsial pendapatan $\left(\mathrm{X}_{3}\right)$ mendapatkan $\mathrm{t}$ hitung $(2,827)$ melebihi $\mathrm{t}$ tabel $(1,985)$ dengan sig $0,006<0,05$ sehingga penolakan $\mathrm{H}_{0}$ dan penerimaan $\mathrm{H}_{1}$. Hasil peneltian ini memberi gambaran jika pendapatan secara parsial memberi pengaruh postif dan signfikan terhadap kesejahteraan lansiadi Kecamatan Mengwi. Nilai koefisien regresi dari pendapatan $\left(\mathrm{X}_{3}\right)$ adalah sebesar 0,053 yang artinya apabila pendapatan lansia mengalami peningkatan pendapatan lansia senilai Rp.1000.000 mampu meningkatkankesejahteraan lansia sebesar 0,053 persen dengan asumsi variable lain bernilai konstan. 
Hasil peneltian ini mengambarkan bahwa lansia yang memiliki pendapatan yang tinggi meningkatkan kesejahteraan lansia. Penelitian ini didukung oleh hasil penelitian dari Dominko \& Verbič (2020) yang menyatakan bahwa pendapatan berpengaruh positif dan signifikan terhadap kesejahteraan lansia. Pendapatan memberi pengaruh terhadap kesejahteraan penduduk lanjut usia, dikarenakan pendapatan yang berupa uang merupakan alat untuk memenuhi kebutuhan hidup seseorang. Salah satufaktor kesejahteraan adalah tercukupinya standar kebutuhan hidup yang layak. Hasil penelitian ini juga diperkuat dengan hasil wawancara yang dilakukan dengan salah satu lansia berinisial IGJ yang berasal dari Desa Munggu.

Berdasarkan hasil wawancara tersebut bahwa pendapatan merupakan faktor penting dalam mempengaruhi kesejahteraan lansia. Memiliki pendapatan membuat lansia mampu memenuhi kebutuhan hidupnya. Semakin tinggi pendapatan yang dimiliki oleh lansia membuat kesejahteraan lansia semakin meningkat karena merasa tidak perlu merepotkan untuk memenuhi kebutuhannya. Wang et al., (2019) "menyatakan bahwa seseorang dengan pendapatan yang tinggi memiliki kesejahteraan yang lebih baik. Individu yang memiliki pendaptan yang tinggi memiliki peluang lebih besar untuk mendapatkan apapun yang diinginkan seperti barang dan jasa”. Terpenuhinya kebutuhan yang diinginkan oleh seseorang membuat dirinya semakin dekat untuk mencapai kesejahteraan.

Berdasarkan uraian tersebut maka hal ini sesuai dengan pengujian hipotesis empat yaitu variabel pendapatan secara parsial memberi pengaruh positif terhadap kesejahteraan lansia di Kecamatan Mengwi. 
Putu Yunny Lestari Kartini dan I Nengah Kartika. Analisis Faktor-Faktor yang Mempengaruhi.....

Mengacu pada hasil analisis regresi secara parsial status perkawinan $\left(\mathrm{X}_{4}\right)$ mendapakan t hitung $(2,648)$ melebihi $t$ tabel $(1,985)$ dengan sig $0,010<0,05$ sehingga penolakan $\mathrm{H}_{0}$ dan penerimaan $\mathrm{H}_{1}$. Hasil peneltian ini memberi gambaran jika lansia yang berstatus kawin memiliki tingkat kesejahteraan lebihtinggi di bandingkan denganlansia yang berstatus belum menikah/janda/duda di Kecamatan Mengwi. Nilai koefisien regresi dari status perkawinan $\left(\mathrm{X}_{4}\right)$ adalah sebesar 0,087 yang artinya jika lansia yang berstatus kawin $(D=1)$ mempunyai kesejahteraan lebih tinggi senilai $0,087 \%$ jika dibandingkan terhadap lansia yang memiliki status belum kawin/janda/duda $(\mathrm{D}=0)$.

Penelitian ini didukung oleh hasil penelitian dari Astuti (2019) yang menyatakan bahwa status perkawinan berpengaruh positif dan signifikan terhadap kualitas hidup lansia. Menurut Gutiérrez-Vega \& Villar (2018) sesorang yang bercerai atau tidak mempunyai pasangan memiliki kualitas hidup lebih rendah dibandingkan dengan seseorang yang memiliki status menikah.

Lansia yang dihadapkan dengan berbagai macam peristiwa dan kejadian kehidupan yang membuat perubahan-perubahan yang mampu menimbulkan stress. Peristiwa kehidupan yang terjadi pada lansia antara lain peristiwa kehilangan pasangan hidup atau orang yang dicintai berdampak pada fungsi psikologis yang membuat lansia menolak kondisi saat ini, menjadi pendiam, pemarah, pemurung, pencemas sampai kondisi depresi. Hal tersebut berpengaruh pada kualitas hidupnya sehingga membuat kesejahteraan lansia tersebut menurun. 
Hasil penelitian ini juga diperkuat dengan hasil wawancara yang dilakukan terhadap salah satu lansia berinisial IGNR yang berasal dari Desa Pererenan. Berdasarkan hasil wawancara tersebut bahwa status perkawinan merupakan faktor penting dalam mempengaruhi kesejahteraan lansia. Kebutuhan untuk dicintai dan mencintai bagi lansia di masa tuanya sangat berpengaruh terhadap kualitas hidupnya, karena dengan memiliki pasangan hidup di masa tuanya lansia akan merasa berharganya dirinya utntuk orang lain yang dicintainya (Astuti, 2019).

Mengacu pada uraian diatas, hal tersebut sesuai dengan pengujian hipotesis lima yaitu lansia yang berstatus kawin memiliki tingkat kesejahteraan lebih tinggi di bandingkan terhadap lansia yang memiliki status belum menikah/janda/duda di Kecamatan Mengwi.

Mengacu pada hasil analisis regresi secara parsial akses kesehatan $\left(\mathrm{X}_{5}\right)$ mendapatkan $\mathrm{t}$ hitung $(2,170)$ melebihi $\mathrm{t}$ tabel $(1,985)$ dengan sig $0,033<0,05$ sehingga penolakan $\mathrm{H}_{0}$ penerimaan $\mathrm{H}_{1}$. Hasil peneltian ini memberi gambaran jika lansia yang memiliki akses kesehatan memiliki tingkat kesejahteraan lebihtinggi di bandingkandengan lansia yang tidak memiliki akses kesehatan di Kecamatan Mengwi. Nilai koefisien regresi dari akses kesehatan $\left(\mathrm{X}_{5}\right)$ adalah sebesar 0,059 yang artinya apabila lansia yang memiliki akses kesehatan $(D=1)$ tingkat kesejahteraannya lebih tinggi sebesar $0,059 \%$ dibandingkan terhadap lansia yang tidak memiliki akses kesehatan $(\mathrm{D}=0)$.

Hasil penelitian ini menunjukkan jika lansia yang memiliki akses kesehatan tingkat kesejahteraannya lebih tinggi dibandingkan dengan lansia yang tidak 
Putu Yunny Lestari Kartini dan I Nengah Kartika. Analisis Faktor-Faktor yang Mempengaruhi.....

memiliki akses kesehatan. Penelitian ini didukung oleh hasil penelitian dari Dominko \& Verbič (2020) yang menyatakan jika akses kesehatan memberi pengaruh positif dan signifikan terhadap kesejahteraan lansia.

Hasil penelitian ini juga diperkuat dengan hasil wawancara yang dilakukan dengan seorang lansia berinisial NPR yang berasal dari Desa Kapal. Berdasarkan hasil wawancara tersebut bahwa akses kesehatan merupakan faktor penting dalam mempengaruhi kesejahteraan lansia. Akses layanan kesehatan yang berkualitas diperlukan untuk pencapaian kesetaraan kesehatan dan untuk meningkatkan kualitas hidup sehat bagi lanjut usia.

Dalam meningkatkan akses pelayanan kesehatan bagi lansia pemerintah memerlukan berapa langkah yang berbeda yaitu mendapatkan kesempatan masuk ke dalam sistem pelayanan kesehatan; dapat mengakses tempat pelayanan kesehatan dan dapat berkomunikasi dan mempercayai pemberi pelayanan kesehatan. Kepemilikan akses kesehatan oleh lansia akan mempermudah lansia dalam berobat atau memenuhi kebutuhan kesehatan, sehingga bagi lansia yang memiliki akses kesehatan akan memiliki kesejahteraan yang lebih tinggi dibandingkan yang tidak memiliki akses kesehatan.

Mengacu pada uraian diatas, sehingga hal ini sesuai terhadap pengujian hipotesis enam yaitu lansia yang memiliki akses kesehatan memiliki tingkat kesejahteraan lebih tinggi jika di bandingkan dengan lansia yang tidak memiliki akses kesehatan di Kecamatan Mengwi. 
Mengacu pada analisis regresi linier berganda diketahui jika variabel status ketenagakerjaan $\left(\mathrm{X}_{2}\right)$ mempunyai nilai absolut standardized coefficient beta tertinggi yaitu senilai 0,268. Hasil penelitian memberi gambaran bahwa jika lansia bekerja dan memiliki penghasilan sendiri, maka kesejahteraan lansia tersebut akan meningkat. Bekerja membuat lansia memiliki kegiatan, mampu berinteraksi dengan orang lain sehingga tidak merasakan kesepian, dan mampu memiliki penghasilan sendiri tanpa mebebani anak ataupun keluarganya. Hasil penelitian menunjukkan bahwa status ketenagakerjaan merupakan faktor dominan yang mempengaruhi kesejahteraan lansia di Kecamatan Mengwi, Kabupaten Badung.

Bekerja membuat penduduk lansia dapat meningkatkan kemandiriannya dalam memenuhi kebutuhan sehari-hari dan mengisi waktu luang daripada tidak memiliki kegiatan atau menganggur, selain itu dengan bekerja penduduk lansia tidak ingin menjadi beban keluarga, terutama anak atau merasa tinggal sendiri di rumah karena ditinggal merantau anak-anaknya. Penduduk lansia yang bekerja akan memiliki tingkat kesejahteraan yang lebih tinggi dibandingkan dengan penduduk lansia yang tidak bekerja.

Dalam bermasyarakat lansia dianggap sebagai individu yang lemah, bergantung dengan orang disekitarnya, dan tidak berproduktif karena pada umumnya sudah mulai menghadapi penurunan kemampuan fisik maupunpsikis. Lansia memiliki harapan diusia senjanya tetap dapat menikmati kesejahteraan hidup walaupun menghadapi penyakit dan penurunan kesehatan, sehingga faktorfaktor yang tidak disebutkan diatas, seperti tingkatpendidikan, status 
Putu Yunny Lestari Kartini dan I Nengah Kartika. Analisis Faktor-Faktor yang Mempengaruhi.....

ketenagakerjaan, pendapatan, statusperkawinan, dan akses kesehatan menjadi menarikdiamati.

Tingkat pendidikan lansia yang dilihat dari tahun suksesnya secara umum adalah rendah, yang dapat dilihat dari kategori SD kebawah dan hanya beberapa yang mampu melanjuti ke jenjang pendidikan yang lebih tinggi yang dikarenakan keterbatasan biaya yang dimiliki orang tua pada saat itu. "Melalui pendidikan, seseorang akan mendapatkan banyak wawasan dan ilmu pengetahuan untuk dapat mengembangkan potensi diri agar dapat mencapai kehidupan yang sejahtera. Selain itu, pendidikan mampu membuat seseorang mendapatkan pekerjaan yang layak dengan penghasilan yang mencukupi”. Tidak hanya bermanfaat saat lansia pada usia produktif, pendidikan lansia yang tinggi juga berguna saat lansia menjalani hidup di masa tuanya seperti mengaktualisasikan dirinya sesuai dengan kemampuan dan keahlian untuk menjalani hidup dengan sebaik-baiknya.

Bekerja adalah suatu pilihan bagi lansia, dalam kondisi apapun penduduk lansia dapat memilih tetap bekerja atau tidak dalam menikmati ataupun mengisi kegiatan sehari-hari di masa tuanya. Penduduk lansia yang bekerja memiliki tingkat kesejahteraan yang lebih tinggi dibandingkan dengan penduduk lansia yang tidak bekerja. Penduduk lansia yang tetap bekerja menunjukkan kemandirian mereka untuk tidak ketergantungan dengan orang lain sekaligus sebagai aktualisasi diri, selain itu bekerja juga membuat lansia mampu memenuhi kebutuhannya yang dirasa masih kurang. 
Bagi lansia yang sudah tidak bekerja, cenderung mempunyai sedikit kegiatan dan banyak waktu luang. Sedikitnya kegiatan yang dimiliki ini akan memunculkan rasa bosan pada lansia, yang mengakibatkan terjadinya depresi (Prabhaswari, 2016), namun beberapa lansia yang tidak bekerja mereka akan menghabiskan dan menikmati kehidupan sehari-harinya bersama dengan anggota keluarga.

Pendapatan lansia pada umumnya adalah rendah, namun terdapat beberapa lansia yang memiliki pendapatan tinggi. Umumnya lansia yang memiliki pendapatan rendah adalah lansia yang pada usia produktifnya tidak memiliki pekerjaan yang baik, sehingga pada masa tuanya hanya menerima pemberian dari anak atau anggota keluarga ataupun santunan pemerintah, bahkan masih banyak lansia yang memilih untuk bekerja agar dapat memenuhi kebutuhan sehari-harinya tanpa membebani keluarganya.

Lansia pada umumnya berstatus kawin atau memiliki pasangan. Lansia yang memiliki status kawin mempunyai kesejahteraan yang tinggi dibanding terhadap lansia yang berstatus belum kawin/janda/duda. Keberadaan pasangan menjadi salah satu hal yang penting bagi lansia dikarenakan pasangan dapat menjadi tempat ternyaman untuk bercerita dan menjadi teman dalam menikmati kehidupan di masa tuanya (Carr et al., 2015).

Pada umumnya hampir semua lansia memiliki akses kesehatan. Lansia yang memiliki akses kesehatan akan lebih sejahtera dibandingkan dengan lansia yang tidak memiliki. Kepemilikan akses kesehatan mejadi salah satu hal yang penting bagi lansia untuk menjaga kesehatannya. Bagi lansia yang memiliki akses 
Putu Yunny Lestari Kartini dan I Nengah Kartika. Analisis Faktor-Faktor yang Mempengaruhi.....

kesehatan akan memudahkan lansia tersebut untuk berobat, sehingga para lansia tidak akan takut, merasa khawatir atau merasa terbebani untuk masalah biaya, jarak rumah dengan pelayan kesehatan dan kelengkapan fasilitas kesehatan. Lansia yang renta denga masalah kesehatan akan dapat memenuhi kebutuhan kesehatannya dengan akses kesehatan yang dimiliki. Akses layanan kesehatan yang berkualitas diperlukan untuk pencapaian kesetaraan kesehatan dan untuk meningkatkan kualitas hidup sehat bagi lanjut usia

\section{SIMPULAN DAN SARAN}

“Tingkat pendidikan, status ketenagakerjaan, pendapatan, status perkawinan dan akses kesehatan berpengaruh secara simultan dan signifikan terhadap kesejahteraan lansia di Kecamatan Mengwi, Kabupaten Badung. Kelima variabel bebas mampu menjelaskan 57 persen perubahan dalam kesejahteraan lansia di Kecamatan Mengwi, Kabupaten Badung dan sisanya sebesar 43 persen merupakan pengaruh variabel lain yang tidak diteliti."

“Tingkat pendidikan secara parsial berpengaruh positif dan signifikan terhadap kesejahteraan lansia di Kecamatan Mengwi, Kabupaten Badung. Lansia yang bekerja memiliki tingkat kesejahteraan lebih tinggi di bandingkan dengan lansia yang sudah tidak bekerja di Kecamatan Mengwi, Kabupaten Badung. Pendapatan secara parsial berpengaruh positif dan signifikan terhadap kesejahteraan lansia di Kecamatan Mengwi, Kabupaten Badung. Lansia yang berstatus kawin memiliki tingkat kesejahteraan lebih tinggi di bandingkan dengan lansia yang berstatus belum menikah/janda/duda di Kecamatan Mengwi, 
Kabupaten Badung. Lansia yang memiliki akses kesehatan memiliki tingkat kesejahteraan lebih tinggi di bandingkan dengan lansia yang tidak memiliki akses kesehatan di Kecamatan Mengwi, Kabupaten Badung. Sehingga secara parsial Tingkat pendidikan, statusketenagakerjaan, pendapatan, status perkawinan dan akses kesehatan berpengaruh dan signifikan terhadap kesejahteraan lansia di Kecamatan Mengwi, Kabupaten Badung.

Berdasarkan hasil analisis dan simpulan diatas, maka dapat diajukan beberapa saran sebagai berikut : Penduduk lansia diharapkan mampu memanfaatkan bekal pendidikan, pendapatan dan akses kesehatan yang dimiliki untuk menjalani kehidupan sebaik-baiknya. Bagi lansia yang masih bekerja agar bekerja sesuai kemampuan dan tetap memperhatikan kesehatan. Bagi lansia yang masih tinggal bersama suami/istri beserta anak, cucu, atau anggota keluarga lainnya, sebaiknya tetap menjaga komunikasi dalam keluarga.

Bagi pemerintah dan dinas yang terkait untuk meningkatkan kualitas data penduduk lanjut usia di masing-masing wilayah, sehingga mudah untuk di data guna kepentingan penelitian ataupun kebijakan pemerintah, pemerintah juga diharapkan dapat meningkatkan pelayanan kesejahteraan sosial bagi lansia yang merata pada setiap wilayah, dan pemerintah diharapkan dapat meningkatkan kegiatan untuk para lansia agar nantinya dapat menjadi lansia yang aktif dan mandiri.

\section{REFERENSI}

Adebowale, S. A., Atte, O., \& Ayeni, O. (2015). Elderly Well-Being in a Rural Community in North Central Nigeria, Sub-Saharan Africa. Public Health 
Putu Yunny Lestari Kartini dan I Nengah Kartika. Analisis Faktor-Faktor yang Mempengaruhi.....

Research, 2(4), 92-101."

Aini, E., Isnaini, I., Sukamti, S., \& Amalia, L. (2018). Pengaruh Tingkat Pendidikan Terhadap Tingkat Kesejahteraan Masyarakat di Kelurahan Kesatrian Kota Malang. Technomedia Journal, 3(1), 58-72.

Ascroft, V., \& Cavanough., D. (2018). Survey of Recent Developments. Bulletin of Indonesian Economic Studies, 44(3), 335-363.

Astuti, A. D. (2019). Status Perkawinan Meningkatkan Kualitas Hidup Lansia di PSTW Sinta Rangkang Tangkiling Kalimantan Tengah. Jurnal Keperawatan Dan Kesehatan Masyarakat, 8(2), 1-8.

Calys-Tagoe, B., Hewlett, S., Dako-Gyeke, P., Yawson, A., Bad-Doo, N., Seneadza, N., \& Biritwum, R. (2015). Predictors of Subjective Well-Being Among Older Ghanaians. Ghana Medical Journal, 48(4), 178.

Carr, D., Freedman, V. A., Cornman, J. C., \& Schwarz, N. (2015). Happy Marriage, Happy Life? Marital Quality and Subjective Well-being in Later Life. Journal of Marriage and Family, 76(1), 960-948.

Dewi, I. G. A. K. C., Suyana Utama, M., \& Marhaeni, A. (2016). Pengaruh Faktor Ekonomi, Sosial dan Demografi Terhadap Kontribusi Perempuan Pada Pendapatan Keluarga di Sektor Informal Kecamatan Melaya, Kabupaten Jembrana. Jurnal Piramida, 12(1), 38-47.

Dewi Utami, N. P., \& Rustariyuni, S. D. (2016). Pengaruh Variabel Sosial Demografi Terhadap Keputusan Penduduk Lanjut Usia Memilih Untuk Bekerja Di Kecamatan Kediri Kabupaten Tabanan . Jurnal Ekonomi Kuantitatif Terapan, 9(2), 89-176.

Dharmayanti, N. P. A. P., Sudibia, K., \& Urmila Dewi, N. M. H. (2017). Peran Akses Kesehatan Dalam Memediasi Variabel Pendapatan, Tingkat Pendidikan dan Status Ketenagakerjaan Terhadap Kesejahteraan Penduduk Lanjut Usia di Kota Denpasar. E-Jurnal Ekonomi Dan Bisnis Universitas Udayana, 6(5), 1995-2020.

Dominko, M., \& Verbič, M. (2020). The Effect of Income and Wealth on Subjective Well-Being in the Context of Different Welfare State Regimes. Journal of Happiness Studies, 1(1), 1-10.

Eshkoor, S. ., Hamid, T. A., Mun, C. Y., \& Shahar, Z. (2015). An Investigation on Predictors of Life Satisfaction Among the Elderly. International E-Journal of Advances in Social Sciences, 1(2), 2017-2212.

Gutiérrez-Vega, M., \& Villar. (2018). The Possible Protective Effect of Marital 
Status in Quality of Life Among Elders in a U.S.-Mexico Border City. Community Ment Health J., 54(4), 480-484.

Huang, W. H., Lin, Y. J., \& Lee, H. F. (2019). Impact of population and workforce aging on economic growth: Case study of Taiwan. Sustainability (Switzerland), 11(22), 1-13. https://doi.org/10.3390/su11226301

Hukom, A. (2015). Hubungan Ketenagakerjaan Dan Perubahan Struktur Ekonomi terhadap Kesejahteraan Masyarakat. Jurnal Ekonomi Kuantitatif Terapan, $7(2), 201-129$.

Kim, C.-B., Yoon, S.-J., \& Ko, J. (2017). Economic Activity and Health Conditions in Adults Aged 65 Years and Older: Findings of the Korean National Longitudinal Study on Aging. Healthcare (Basel), 5(4), 63.

Kurniawan, J. (2016). Dilema Pendidikan dan Pendapatan di Kabupaten Grobogan. Jurnal Ekonomi Kuantitatif Terapan, 9(1), 56-97.

McDonald, P. (2015). The Demography of Indonesia in Comparative Perspective. Bulletin of Indonesian Economic Studies, 50(2), 29-52.

Rahayu, S. U., \& Tisnawati, N. M. (2015). Analisis Pendapatan Keluarga Wanita Single Parent (Studi Kasus Kelurahan Sesetan, Kecamatan Denpasar Selatan, Kota Denpasar). Jurnal Ekonomi Kuantitatif Terapan, 7(2), 83 - 89.

Rammohan, A., \& Magnani, E. (2015). Modelling the influence of caring for the elderly on migration: estimates and evidence from Indonesia. Bulletin of Indonesian Economic Studies, 48(3), 399-420.

Seran, S. (2017). Hubungan antara Pendidikan, Pengangguran, dan Pertumbuhan Ekonomi dengan Kemiskinan. Jurnal Ekonomi Kuantitatif Terapan, 10(1), $59-71$.

Sriastiti, Ni Made Ayu. (2018). Analisis Determinan Kesejahteraan Lansia di Kabupaten Tabanan. E-JurnalEP Unud, 7 (10): 2218-2248.

Sudibia, I. K., \& Kartika, N. P. R. D. (2015). Pengaruh variabel sosial demografi dan sosial ekonomi terhadap partisipasi kerja penduduk lanjut usia. E-Journal EP Udayana, 3(6), 247-256.

Thomas, P. A., Liu, H., \& Umberson, D. (2017). Family Relationships and WellBeing. Innov Aging, 1(3), 1-20.

Wang, S., Chan, K., \& Han, K. (2019). Impacts of social welfare system on the employment status of low-income groups in urban China. Public Administration and Policy, 22(2), 125-137. https://doi.org/10.1108/pap-09- 
2019-0020

Wenas, G. E., Opod, H., \& Cicilia, P. (2015). Hubungan Kebahagiaan dan Status Sosial Ekonomi Keluarga di Kelurahan Artembaga II Kota Bitung. Jurnal EBiomedik (EBm), 3(1), 532-538.

Yamada, T., Chen, C.-C., Murata, C., Hirai, H., Ojima, T., Kondo, K., \& Harris, J. R. (2015). Access Disparity and Health Inequality of the Elderly: Unmet Needs and Delayed Healthcare. Int J Environ Res Public Health, 12(2), 17451772. https://doi.org/10.3390/ijerph120201745

Zarulli, V., Jones, J. A. B., Oksuzyan, A., Lindahl-Jacobsen, R., Christensen, K., \& Vaupel, J. W. (2018). Women live longer than men even during severe famines and epidemics. Proc Natl Acad Sci U S A, 115(4), E832-E840. 